\title{
The role of impurities in the $\mathrm{La}_{2} \mathrm{O}_{3}$ catalysed carboxylation of crude glycerol
}

\author{
N. A. Razali ${ }^{1} \cdot$ M. Conte $^{2} \cdot$ J. McGregor ${ }^{1}$
}

Published online: 15 February 2019

(c) The Author(s) 2019

\begin{abstract}
The direct carboxylation of crude glycerol, obtained as a by-product of bio-diesel synthesis, with $\mathrm{CO}_{2}$ has been investigated over lanthanum oxide as a heterogeneous catalyst for the first time. Adiponitrile is employed as a dehydrating agent in order to shift the reaction equilibrium to the product side. The selectivity of the reaction towards glycerol carbonate when using crude glycerol is significantly reduced as compared to employing refined glycerol: $2.3 \%$ cf. $17 \%$ respectively. Glycerol conversion, however remains approximately constant: $54 \% \mathrm{cf}$. 58\%. In order to understand the role of the impurities present in crude glycerol, model systems consisting of refined glycerol and one or more of water, methanol, methyl palmitate (as a model fatty acid methyl ester), and sodium methoxide have been prepared and used as reaction media to systematically evaluate their effect. All of these impurities are seen to reduce the selectivity towards glycerol carbonate, instead favouring the formation of 4-(hydroxymethyl)oxazolidin-2-one, with the exception of methanol where no detrimental effect is observed and the measured selectivity increases slightly to ca. $22 \%$. This effect is ascribed, in part, to improved mass transfer as a consequence of an increased solubility of carbon dioxide in the liquid media when methanol is present. Additionally, adiponitrile is observed to play a crucial role in the reaction mechanism beyond its simple role as a dehydrating agent. These results provide insights into the required purification steps for crude glycerol, and suggest the possibility of employing crude glycerol directly, and its use as a chemical feedstock; in both cases by minimising costly separation and purification steps.
\end{abstract}

\section{Graphical Abstract}

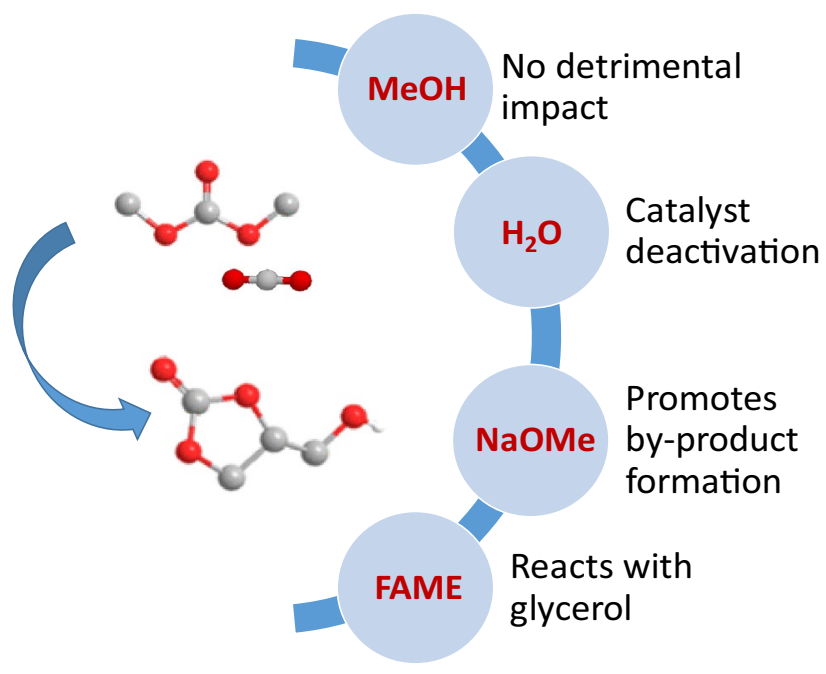

Keywords Glycerol · Carbon dioxide utilisation · Glycerol carbonate $\cdot$ Lanthanum oxide $\cdot$ Glycerin $\cdot$ Carboxylation of crude glycerol $\cdot$ Heterogeneous catalysis · Adiponitrile

Extended author information available on the last page of the article 


\section{Introduction}

Glycerol is the major by-product arising from the production of biodiesel, with $1 \mathrm{~kg}$ of glycerol produced for every $10 \mathrm{~kg}$ of biodiesel [1]. It is estimated that approximately $67 \%$ of global glycerol production is derived from biodiesel synthesis [2]. However, one of the major challenges resulting from the increasing commercialisation of biodiesel is the disposal of waste glycerol, a costly process which can create environmental concern [3]. This has the consequence of lowering the market value of both refined and crude glycerol $[4,5]$. Therefore, methods able to utilise glycerol through conversion to value-added products such as glycerol carbonate present an excellent opportunity to offset both economic and environmental concerns. Further, there are clear benefits to minimising the number of pre-treatment steps required in order to utilise crude glycerol, that is glycerol directly obtained from the synthesis of biodiesel and without further purification.

Crude glycerol consists of: glycerol, methanol, residual catalyst from biodiesel synthesis, fatty acid methyl esters (FAMEs) and water [2]. The presence of these impurities can limit the direct conversion of crude glycerol and lead to products or processes with a low yield, e.g., as a consequence of catalyst poisoning. This can make utilisation of crude glycerol unfavourable in many circumstances. Distillation, filtration, chemical treatment, adsorption using activated carbon, ion-exchange, extraction and crystallization are the typical methods employed to purify crude glycerol [6], and in turn at significant processing cost; the costs of separation and purification often dominate the overall cost of a chemical process [7]. This has therefore stimulated recent research on the direct utilisation of crude glycerol into valuable chemicals, e.g. glycerol carbonate [8, 9], polyester [10], 1,3-propanediol [11], and $n$-butanol [12]. Glycerol carbonate is of particular interest due to its varied potential applications as an electrolyte in lithium ion batteries, an intermediate in polymer synthesis and wide use in the cosmetic and pharmaceutical industries [13, 14]. Additionally, glycerol carbonate has been proposed as a solvent for the pre-treatment of sugarcane bagasse [15] suggesting a role for this versatile chemical in low and middle income agricultural economies where small-scale, local, biodiesel production may play an important role in sustainable energy generation, but where complex separation processes are not available.

Glycerol carbonate can be produced from glycerol through reaction with phosgene or via transesterification with dimethyl or diethyl carbonate $[16,17]$, however these acyclic organic carbonates are themselves commonly manufactured from phosgene [18]. Alternatives to employing phosgene include the use of urea [19-21]. This route has the advantages that urea is relatively inexpensive and the reaction can be carried out in the absence of a solvent, however this reaction produces ammonia as a waste product [22, 23]. The ammonia produced may promote the formation of isocyanic acid, therefore it is necessary to employ a vacuum system in order to remove $\mathrm{NH}_{3}$ [22, 24]. A promising alternative is the direct carboxylation of glycerol with $\mathrm{CO}_{2}$ [25]. The use of $\mathrm{CO}_{2}$ also has advantages in making use of a highly available, low cost, waste material which contributes directly to climate change; $\mathrm{CO}_{2}$ concentration in the atmosphere having reached $411 \mathrm{ppm}$ in May 2018 [26]. The direct carboxylation of glycerol can therefore be considered as a green process, but it is thermodynamically limited [27] having a small chemical equilibrium constant: $1.3 \times 10^{-3}$ at $160{ }^{\circ} \mathrm{C}$ and $5 \mathrm{MPa}$ [28]. Therefore, the reaction must be carried out at high pressure, > $5 \mathrm{MPa}$, and elevated temperature.

In order to overcome this limitation, acetonitrile [29], 2-cyanopyridine [25] and benzonitrile [30] have previously been employed as dehydrating agents in this reaction. Dehydrating agents act as a chemical water trap, thus shifting the equilibrium to the product side; additionally 2-cyanopyridine has also been implicated in $\mathrm{CO}_{2}$ activation [31]. A range of heterogeneous catalysts have previously been employed and tested for the conversion of glycerol to glycerol carbonate including: zeolites, basic ion-exchange resins as well as $\mathrm{Al}_{2} \mathrm{O}_{3}$ and $\mathrm{Nb}_{2} \mathrm{O}_{5}$ supported on $\mathrm{CeO}_{2}$ [32-34]. Employing $\mathrm{CeO}_{2}$ directly as a catalyst resulted in an $19 \%$ yield to glycerol carbonate [31]. The use of $\mathrm{La}_{2} \mathrm{O}_{2} \mathrm{CO}_{3}-\mathrm{ZnO}$ [29], $\mathrm{Cu} / \mathrm{La}_{2} \mathrm{O}_{3}$ [35] and $\mathrm{Cu}$ based catalysts supported on: (i) acidic supports; (ii) basic supports; (iii) acidic and basic bifunctional supports; and (iv) supports with neither acidic nor basic sites for the carboxylation of glycerol in the presence of acetonitrile have also been studied [36, 37]. Transition metals have demonstrated potential to activate $\mathrm{CO}_{2}$; however the performance of these catalysts is highly dependent upon metal particle size and the degree of metal dispersion [35, 36]. Elsewhere, hydrotalcite catalysts such as $\mathrm{Zn} / \mathrm{Al} / \mathrm{La} / \mathrm{M}(\mathrm{M}=\mathrm{Li}$, $\mathrm{Mg}$ and $\mathrm{Zr}$ ) and $\mathrm{Zn} / \mathrm{Al} / \mathrm{La} / \mathrm{X}(\mathrm{X}=\mathrm{F}, \mathrm{Cl}$ and $\mathrm{Br}$ ) have been employed resulting in yields of glycerol carbonate of up to $14 \%[29,30,38]$.

Considering the use of crude, unrefined glycerol as a feedstock, Okoye et al. [39] have studied the influence of water in the synthesis of glycerol carbonate synthesis from dimethyl carbonate and they observed a strong decrease in carbonate yield from 75 to $50 \%$ upon the addition of $5 \mathrm{wt} . \%$ of water. Elsewhere, Teng et al. [9] studied the microwaveassisted transesterification of crude glycerol over a $\mathrm{CaO}$ catalyst. In this case, a yield of glycerol carbonate of $94 \%$ was achieved if in the presence of sodium methoxide (NaOMe); in contrast a yield of only $8 \%$ was achieved if using pure glycerol under the same reaction conditions. 
Further attempts at synthesising glycerol carbonate from crude glycerol have been made via the glycerolysis of urea. Indran and co-workers reported that the presence of water significantly reduced the conversion of glycerol from 94 to $50 \%$ and the yield of glycerol carbonate from 85 to $35 \%$; an effect ascribed to the instability of glycerol carbonate in water [8]. This study also revealed that methanol has a negative effect on the glycerolysis of urea, as it promotes the decarboxylation of glycerol carbonate to glycidol.

The present work therefore extends these previous studies by investigating the direct carboxylation of crude glycerol with $\mathrm{CO}_{2}$ in the presence of adiponitrile as a dehydrating agent over lanthanum based catalysts. This has the advantages of overcoming the thermodynamic limitations of the reaction through the use of a dehydrating agent, and of improving the overall economic and environmental sustainability of the process by avoiding the use of phosgene and bypassing the separation and purification of crude glycerol. $\mathrm{La}_{2} \mathrm{O}_{3}$ is widely used in the carboxylation of pure glycerol to glycerol carbonate directly as a single component catalyst, mixed metal oxide or a support and hence its use allows direct comparison with previous studies of this reaction [40-43].

\section{Materials and Experimental Method}

\subsection{Characterisation of Crude Glycerol}

Crude glycerol was obtained as the by-product of biodiesel synthesis from sunflower oil and methanol, catalysed by sodium methoxide. The reaction was carried out on a Golden Ray biodiesel processer. The composition of all organic species present in the crude glycerol was determined using GC-MS (Shimadzu GC-MS 2010) through comparison with the NIST library. The water content was determined using the Karl Fisher titration method; carried out by Quality Context Limited. The quantity of sodium salt remaining in the crude glycerol was analysed by ICPMS; while the $\mathrm{pH}$ of the crude glycerol was estimated using $\mathrm{pH}$ paper.

\subsection{Catalyst and Reagents}

Commercial $\mathrm{La}_{2} \mathrm{O}_{3}(99.9 \%$, Sigma-Aldrich) was employed as the catalyst. Prior to use the catalysts were calcined at $400{ }^{\circ} \mathrm{C}$ in static air with a heating ramp from room temperature of $40{ }^{\circ} \mathrm{C} \mathrm{min}^{-1}$. Additionally, glycerol (99\%, Sigma-Aldrich) and adiponitrile (99\%, Sigma-Aldrich) were utilised as reagents.

\subsection{Characterisation Techniques}

The morphology of the catalyst was studied by scanning electron microscopy (SEM) (JEOL JSM-6010LA). The solid catalyst was mounted on carbon and gold coated prior to study, and particle size analysis was conducted using Image $\mathbf{J}$ software. Brunauer Emmett Teller (BET) measurements (Micromeritics 3-Flex) identified the total surface area: $0.5 \mathrm{~g}$ catalyst was loaded into the sample tube and degassed at $250{ }^{\circ} \mathrm{C}$ for $3 \mathrm{~h}$ prior to analysis using Vac Prep 061. Surface functionalities were identified by Fourier transform infrared spectroscopy (FTIR) (Shimadzu IRAffinity-IS). Samples were placed in Specac Quest ATR cell and spectra were collected over the range 400 to $4000 \mathrm{~cm}^{-1}$ with a resolution of $4 \mathrm{~cm}^{-1} \mathrm{X}$-ray diffraction (Bruker D2 Phaser) employing $\mathrm{CuK} \alpha 1$ radiation $(\lambda=1.5406 \AA$, monochromator tube voltage $30 \mathrm{kV}$, current $10 \mathrm{~mA}$ ) was used to determine the crystallographic phases present.

In addition, ATR-FTIR was also employed to characterise liquid samples of the reaction mixture. The same spectrometer, accessory and acquisition conditions were used as for the characterisation of the solid catalyst.

\subsection{Catalytic Testing}

Carboxylation of glycerol was carried out over $18 \mathrm{~h}$ in a $45 \mathrm{ml}$ stainless steel autoclave (Parr instrument, Model 4714) equipped with a magnetic stirrer. $\mathrm{La}_{2} \mathrm{O}_{3}(6 \mathrm{wt} . \%$ with regard to the initial reaction mixture), $22.5 \mathrm{mmol}$ of glycerol (2.1 g) and $45 \mathrm{mmol}(5 \mathrm{ml})$ of adiponitrile were loaded into the reactor. The reactor was purged and cycled with $\mathrm{CO}_{2}(2.0 \mathrm{MPa})$. The reactor was then pressurised at $3.4 \mathrm{MPa}$ $\mathrm{CO}_{2}$ at room temperature resulting in an initial pressure at reaction temperature of $4.5 \mathrm{MPa}$. The reactor was placed in an oil bath pre-heated at $160{ }^{\circ} \mathrm{C}$. Once the temperature had stabilised at $160{ }^{\circ} \mathrm{C} \pm 2{ }^{\circ} \mathrm{C}$, the magnetic stirrer was turned on. The reaction was stopped after $18 \mathrm{~h}$ and quenched in ice water. The pressure inside the reactor before and after cooling was recorded and then the reactor was depressurised slowly.

Model crude glycerol mixtures were prepared by mixing glycerol and methanol in an 80:20 mol ratio $(22.5 \mathrm{mmol}$ in total). $1 \mathrm{wt} . \%$ sodium methoxide, $10 \mathrm{wt} . \%$ methyl palmitate (97\%) and/or $10 \mathrm{wt} \% \%$ water were added to the glycerol and methanol mixture. $5 \mathrm{ml}$ of adiponitrile and $6 \mathrm{wt} . \%$ of $\mathrm{La}_{2} \mathrm{O}_{3}$ catalyst were also loaded into the reactor. $2.1 \mathrm{~g}$ of crude glycerol was loaded into the reactor along with $5 \mathrm{ml}$ of adiponitrile and 6 wt. $\%$ of catalyst. 5 wt. $\%$ of methanol and 1 wt.\% of sodium methoxide were also added. Catalytic testing was then conducted following the same methodology as for pure glycerol. 


\subsection{Analysis of Liquid Products}

ATR-FTIR analysis of the liquid samples was conducted employing a Shimadzu IRAffinity-1S. Spectra were collected over the range $400-4000 \mathrm{~cm}^{-1}$ with a resolution of $4 \mathrm{~cm}^{-1}$. Gas chromatography-mass spectrometry (Shimadzu GC-MSQP2012SE) was carried out using a 30 m HP-Innowax capillary column in order to determine the composition of the liquid products collected from the reaction. Ethanol was used as a solvent to dilute samples of the reaction mixture for GC-MS analysis. The conversion of glycerol and selectivity to glycerol carbonate were calculated as follows:

$\%$ conversion $=100 \times\left(\frac{\text { moles of glycerol consumed }}{\text { moles of glycerol introduced }}\right)$

$\%$ selectivity $=100 \times\left(\frac{\text { moles of glycerol carbonate formed }}{\text { moles of glycerol consumed }}\right)$

The yield of glycerol carbonate from glycerol is the product of conversion and selectivity.

\section{Results and discussion}

\subsection{Catalyst Characterisation}

The solid $\mathrm{La}_{2} \mathrm{O}_{3}$ catalyst after calcination at $400{ }^{\circ} \mathrm{C}$ was characterised via SEM (Fig. 1) to determine its morphology and estimate its grain size. The catalyst appears to have a relatively homogenous morphology, with a typical particle size of $\sim 1 \mu \mathrm{m}$.

BET measurements yield a surface area of $13.6 \mathrm{~m}^{2} \mathrm{~g}^{-1}$, and a pore volume, determined from the desorption branch of the isotherm via the BJH method, of $0.015 \mathrm{~cm}^{3} \mathrm{~g}^{-1}$, with an average pore diameter of $3.1 \mathrm{~nm}$. The catalyst

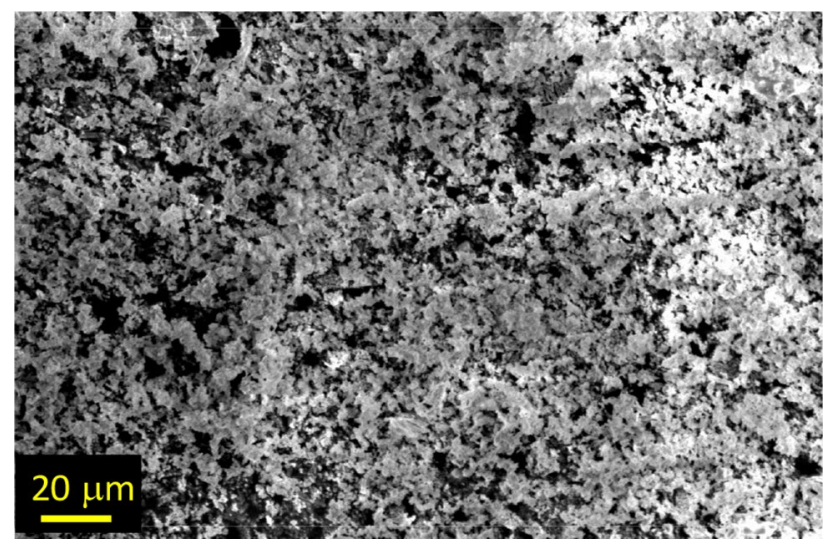

Fig. 1 SEM micrograph of $\mathrm{La}_{2} \mathrm{O}_{3}$. Magnification is $250 \times$ collected with an acceleration voltage of $20 \mathrm{kV}$ can therefore be considered predominately mesoporous in nature. For comparison, the kinetic diameter of glycerol is $0.61 \mathrm{~nm}[44]$ hence mass transfer of the reactant within the catalyst pores is expected to be relatively facile; it therefore more likely that mass transfer between the gas-phase $\left(\mathrm{CO}_{2}\right)$ and the catalyst surface in the liquid (glycerol) phase is the dominant transport-limitation effect.

XRD (Fig. 2) was used in order to confirm the crystalline phase of the $\mathrm{La}_{2} \mathrm{O}_{3}$ catalyst. It is possible to observe the dominant phase is in a hexagonal crystal phase (JCPDS 83-1344); characterised by peaks at $27.5^{\circ}, 28.1^{\circ}, 29.3^{\circ}$, $30.1^{\circ}, 39.6^{\circ}, 46.2^{\circ} 48.9^{\circ}$ and $52^{\circ} 2 \theta$. The presence of $\mathrm{La}(\mathrm{OH})_{3}$ was inferred from the peak at $15.9^{\circ}$ [35]. The formation of $\mathrm{La}(\mathrm{OH})_{3}$ is a result of the interaction of $\mathrm{La}_{2} \mathrm{O}_{3}$ with moisture in atmosphere [35, 45].

Furthermore, due to the basic properties of $\mathrm{La}_{2} \mathrm{O}_{3}$ this can further react with atmospheric $\mathrm{CO}_{2}$ and water [45]. These react on the $\mathrm{La}_{2} \mathrm{O}_{3}$ surface forming the chemisorbed surface carbonate and bicarbonate species, which although not detected via XRD, were confirmed by infrared spectroscopy with characteristic peaks identified at $3608 \mathrm{~cm}^{-1}$ and $634 \mathrm{~cm}^{-1}$ (Fig. 3) [46, 47].

The active phase of the catalyst for the carboxylation reaction is postulated to be $\mathrm{La}_{2} \mathrm{O}_{3} . \mathrm{La}_{2}\left(\mathrm{CO}_{3}\right)_{3}, \mathrm{La}\left(\mathrm{HCO}_{3}\right)_{3}$ both contain $\mathrm{CO}_{2}$ in the form of carbonate $\mathrm{CO}_{3}{ }^{2-}$, which is inert for this reaction, and while $\mathrm{La}(\mathrm{OH})_{3}$ can adsorb $\mathrm{CO}_{2}$ (a pre-requisite to $\mathrm{CO}_{2}$ activation), this adsorption is likely to be very strong and result in reactant poisoning of this phase through the formation of unreactive $\mathrm{La}_{2} \mathrm{CO}_{3}$. By elimination it is therefore suggested that the active phase is $\mathrm{La}_{2} \mathrm{O}_{3}$. Although $\mathrm{La}_{2} \mathrm{O}_{3}$ as a bulk metal oxide is basic [48], the surface contains both Lewis acid sites (uncoordinated $\mathrm{La}^{3+}$ centres) and Lewis basic sites (uncoordinated $\mathrm{O}_{2}{ }^{2-}$ or

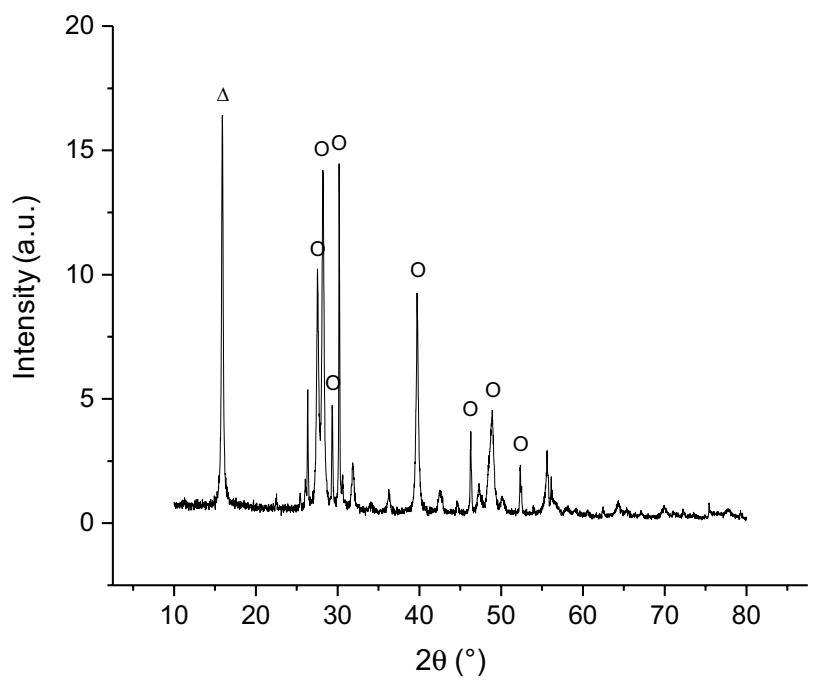

Fig. 2 XRD pattern of $\mathrm{La}_{2} \mathrm{O}_{3}$ catalyst, where $(\Delta)$ indicates $\mathrm{La}(\mathrm{OH})_{3}$ and $(\mathrm{O})$ indicates hexagonal $\mathrm{La}_{2} \mathrm{O}_{3}$ 


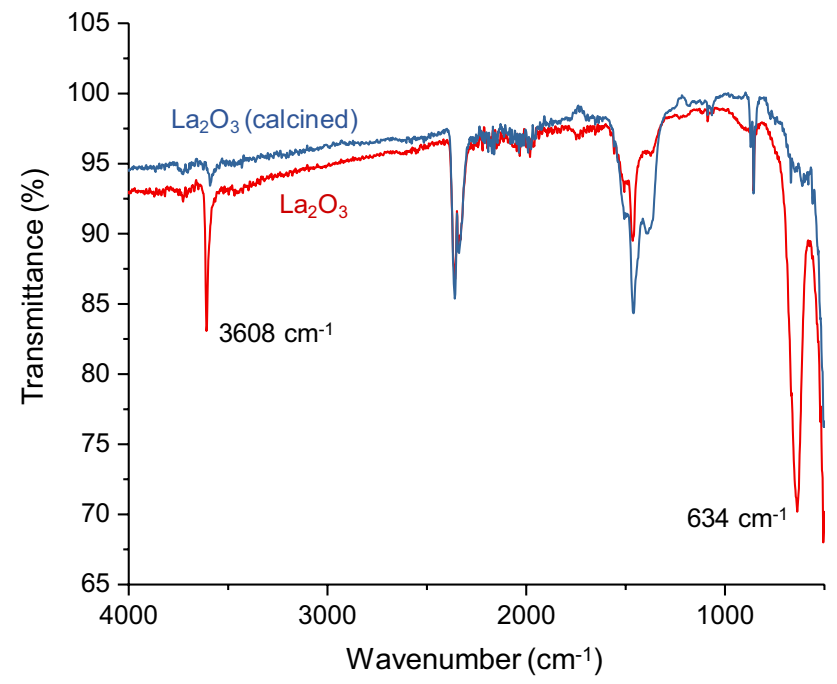

Fig. 3 FTIR spectra of $\mathrm{La}_{2} \mathrm{O}_{3}$ (red) and $\mathrm{La}_{2} \mathrm{O}_{3}$ calcined at $400{ }^{\circ} \mathrm{C}$ (blue). The peaks at $3608 \mathrm{~cm}^{-1}$ and $634 \mathrm{~cm}^{-1}$ are characteristic of surface carbonate and bicarbonate species

$\mathrm{O}_{2}{ }^{2-}$ bridges) [49]. $\mathrm{CO}_{2}$ TPD adsorption studies over $\mathrm{La}_{2} \mathrm{O}_{3}$ surfaces [47] have previously shown that $\mathrm{O}_{2}{ }^{2-}$ can bind $\mathrm{CO}_{2}$ with different levels of strength without necessarily evolving to carbonate species. In view of these data and considerations, it is proposed that it is such $\mathrm{O}_{2}{ }^{2-}$ bridges on the $\mathrm{La}_{2} \mathrm{O}_{3}$ surface that are responsible for the catalytic activity of $\mathrm{La}_{2} \mathrm{O}_{3}$ towards the formation of glycerol carbonate by $\mathrm{CO}_{2}$. This could be confirmed through the application of advanced operando techniques. Additionally, studies on the recyclability of the catalyst would further shed light on the influence of structural and morphological changes on catalyst activity.

\subsection{Characterisation of Crude Glycerol}

The organic species present in crude glycerol were characterised by GC-MS, while the water content was tested using the Karl Fisher titration method. Furthermore, the concentration of sodium, residual from biodiesel synthesis where sodium methoxide forms in situ as the active catalyst, was determined by ICP-MS. The impurities identified in both crude and pure glycerol are summarised in Table 1.

In addition to these impurities, the crude glycerol also contained fatty acid methyl esters (FAMEs), which were analysed via GC-MS, with compound identification through comparison with the NIST database. The chain-length of the detected FAMEs ranged from $\mathrm{C}_{17}$ (methyl palmitate) to $\mathrm{C}_{20}$ (ethyl linoleate). Such compounds are well established constituents of biodiesel synthesised from oil feedstocks [50, $51]$.

\subsection{Direct carboxylation of Glycerol: Comparison of Pure and Crude Glycerol}

By using GC-MS a glycerol conversion of $58 \%$ and a selectivity to glycerol carbonate of $17 \%$ were determined when pure glycerol was used as the feedstock. These values
Table 1 Impurities contained in crude and $99 \%$ purity glycerol. "n.d." indicates that the presence of a component was not detected

\begin{tabular}{lll}
\hline Properties & Crude glycerol (purity 74\%) & Pure glycerol (purity 99\%) \\
\hline Appearance & Brown viscous liquid & Colourless viscous liquid \\
Moisture/ Water (wt/wt\%) & $5 \%$ & $1 \%$ \\
Glycerol purity (wt/wt\%) & $74 \%$ & $99 \%$ \\
Methanol (wt/wt\%) & $<1 \%$ & n.d. \\
$\mathrm{pH}$ & 8 & 7 \\
Salt (g/l) & 6.85 & n.d. \\
\hline
\end{tabular}

Table 2 Impact of individual impurities on the carboxylation of glycerol. Reaction conditions: $\mathrm{P}=4.5 \mathrm{MPa}, 6$ wt. $\% \mathrm{La}_{2} \mathrm{O}_{3}$, $22.5 \mathrm{mmol}$ glycerol, $18 \mathrm{~h}$, $45 \mathrm{mmol}$ adiponitrile and reaction temperature $160^{\circ} \mathrm{C}$

\section{Feedstock composition}

\section{Conversion of} glycerol (\%)

\begin{tabular}{ll}
$\begin{array}{l}\text { Selectivity to glycerol } \\
\text { carbonate }(\%)\end{array}$ & $\begin{array}{l}\text { Yield of glyc- } \\
\text { erol carbonate } \\
(\%)\end{array}$ \\
\hline 17 & 9.9 \\
2.3 & 1.2 \\
22 & 13 \\
11 & 5.6 \\
6.8 & 2.9 \\
1.0 & 0.8 \\
2.6 & 0.5 \\
\hline
\end{tabular}

${ }^{\text {a }}$ Reaction carried out in the absence of $\mathrm{La}_{2} \mathrm{O}_{3}$ 
decreased slightly for the conversion to $54 \%$ and rather significantly to ca. $2.3 \%$ for the selectivity to glycerol carbonate, when crude glycerol is employed (Table 2), indicating that the impurities present have a significant impact on the selectivity of the reaction and that alternative reaction pathways may be operating in the presence of these impurities. These differences are particularly apparent when comparing the yield of glycerol carbonate for both feedstocks where $\mathrm{a} \sim 10$-fold reduction is observed on moving from pure to crude glycerol. This is despite the similarity in overall conversion between the two reactions, which is ascribed to a compensation effect where the decrease in selectivity to, and yield of, glycerol carbonate is compensated by an increase in by-product formation.

In this context though, and for completeness, whereas impurities in crude glycerol play a role for both conversion and selectivity another parameter that may influence the reaction is $\mathrm{pH}$. Crude glycerol has a higher and slightly basic $\mathrm{pH} \sim 8$, as compared to pure glycerol $(\mathrm{pH} \sim 7)$. A higher $\mathrm{pH}$ combined to the presence of water would increase the solubility of $\mathrm{CO}_{2}$ in the reaction mixture, but to the formation of
$\mathrm{H}_{2} \mathrm{CO}_{3}$ and in turn $\mathrm{CO}_{3}{ }^{2-}$, species which are inert towards the reaction of glycerol to glycerol carbonate. This would have an overall effect to decrease the selectivity to glycerol carbonate when crude glycerol is used, in concert with the other effects described in this work.

In addition to glycerol carbonate, 4-(hydroxymethyl) oxazolidin-2-one $\left(\mathrm{C}_{4} \mathrm{H}_{7} \mathrm{NO}_{3}, 4-\mathrm{HMO}\right)$ is formed as a coproduct. In this context parallel reaction pathways leading to glycerol carbonate and 4-HMO are proposed (Fig. 4). It is suggested that 4-HMO is produced from the reaction of glycerol, $\mathrm{CO}_{2}$ and $\mathrm{NH}_{3}$ derived from the decomposition of adipamide. Specifically, $\mathrm{CO}_{2}$ attacks the carbon on the primary and secondary alcohol groups of glycerol to form 2,3-dihydroxypropyl hydrogen carbonate and [2-hydroxy1-(hydroxymethyl)ethyl] hydrogen carbonate. The reaction of these species with $\mathrm{NH}_{3}$ then results in the formation of (2-amino-3-hydroxy-propyl) hydrogen carbonate and [1-(aminomethyl)-2-hydroxy-ethyl] hydrogen carbonate respectively. Cyclisation of these intermediates then leads to the formation of 4-HMO isomers (B1 and B2, Fig. 4). Previous studies on the synthesis of glycerol carbonate employing

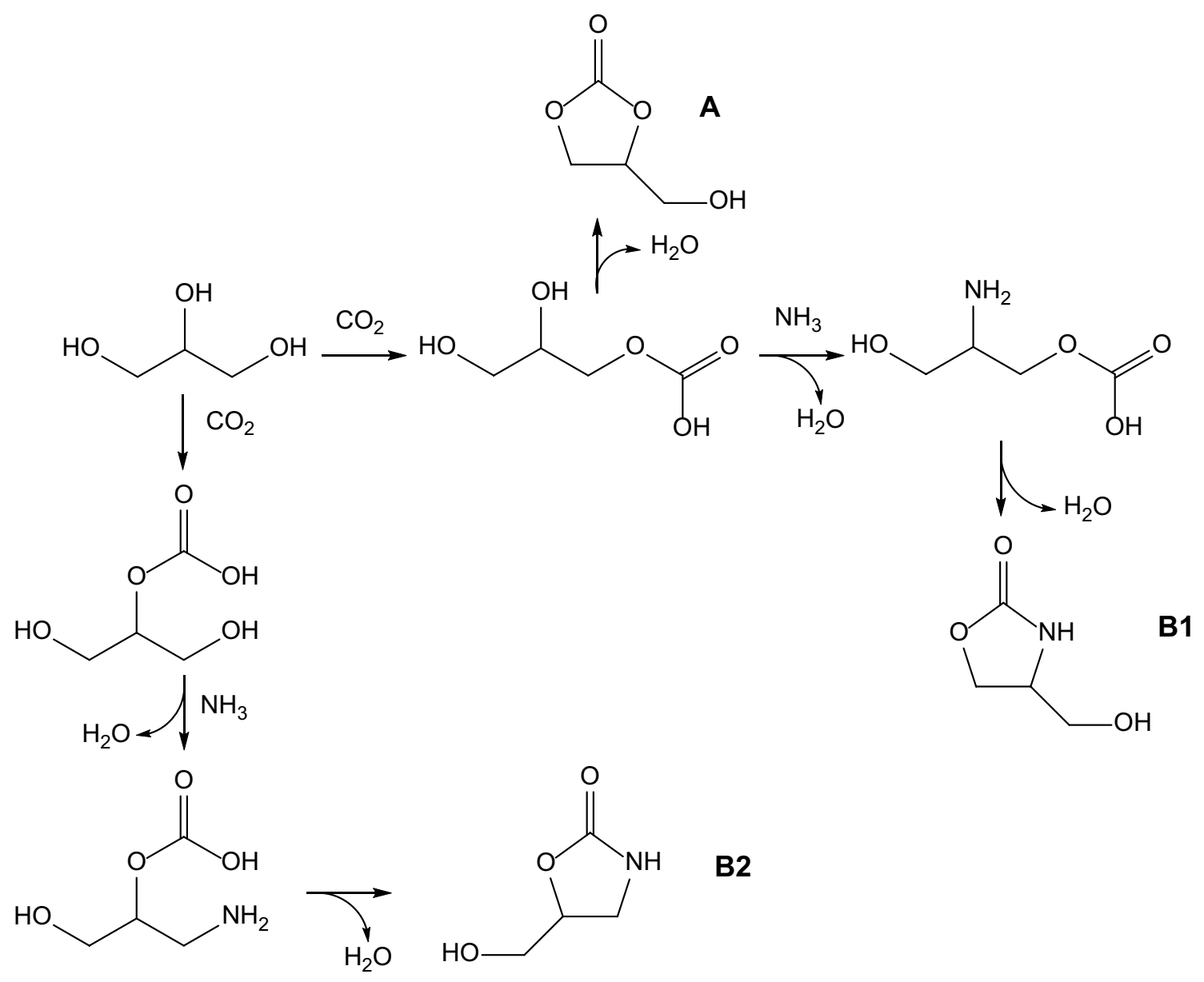

Fig. 4 Parallel reaction pathways of glycerol and carbon dioxide to glycerol carbonate (A) and 4-(hydroxymethyl)oxazolidin-2-one (B1 and B2) 
nitrogen-containing dehydrating agents have identified byproducts such as acetamide but the formation of 4-HMO has not been previously demonstrated [29]. In the present study, the presence of 4-HMO was confirmed by GC-MS analysis using (S)-4-HMO (Sigma-Aldrich) as a standard. In the case of crude glycerol, sodium salts of carboxylic acids ('soap') are an alternative theoretical product. No evidence of soap formation is however observed. This is most likely due to the need for a stoichiometric quantity of sodium methoxide to FAME in the transesterification reaction.

Alongside GC-MS analysis, the liquid products produced have been characterised by FTIR. FTIR spectra for liquid samples arising from the carboxylation of pure and crude glycerol (Fig. 5) showed peaks at 1730 and $1790 \mathrm{~cm}^{-1}$, which are indicative of the presence of a carbonyl $\mathrm{C}=\mathrm{O}$ group within a cyclic five-membered ring. In particular the band at $1790 \mathrm{~cm}^{-1}$ corresponds to the $\mathrm{C}=\mathrm{O}$ of glycerol carbonate, and the band at $1730 \mathrm{~cm}^{-1}$ to the $\mathrm{C}=\mathrm{O}$ of 4-HMO [52]. Notably, this peak at $1730 \mathrm{~cm}^{-1}$ is absent for the reaction employing crude glycerol, and this is consistent with GC-MS analysis which shows only trace amounts of 4-HMO. Note however that glycerol conversion is similar for both pure and crude glycerol, hence these data, as mentioned above, are indicative of the formation of alternative products. These are probably obtained through the rapid transformation of carbonates to an amide product, as indicated by a strong band present in the crude glycerol reaction sample at $1622 \mathrm{~cm}^{-1}$. This is representative of $\mathrm{C}=\mathrm{O}$ of an

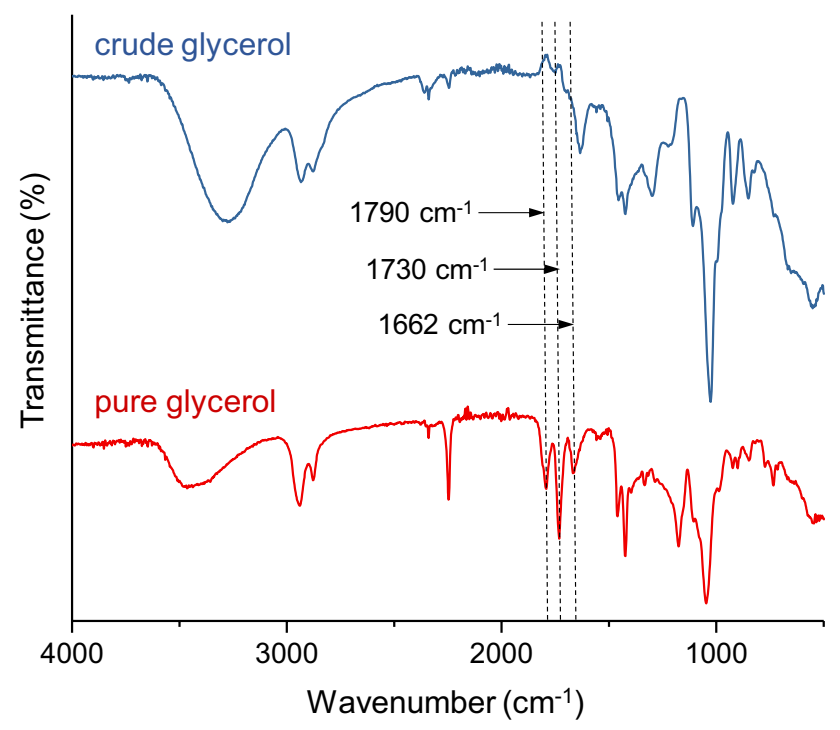

Fig. 5 FTIR spectra of reaction mixtures (liquid sample) of crude (blue) and pure (red) glycerol. Spectra are offset for clarity. Reaction conditions: $\mathrm{P}=4.5 \mathrm{MPa}, 6$ wt. $\%$ of $\mathrm{La}_{2} \mathrm{O}_{3}, 2.1 \mathrm{~g}$ of pure or crude glycerol, $45 \mathrm{mmol}$ of adiponitrile, reaction $\mathrm{T}=160{ }^{\circ} \mathrm{C}$, reaction time $=18 \mathrm{~h}$. The bands at $1790 \mathrm{~cm}^{-1}, 1730 \mathrm{~cm}^{-1}$ and $1662 \mathrm{~cm}^{-1}$ are ascribed to $\mathrm{C}=\mathrm{O}$ of glycerol carbonate, $\mathrm{C}=\mathrm{O}$ of $4-\mathrm{HMO}$ and an aminde funtionality respectively

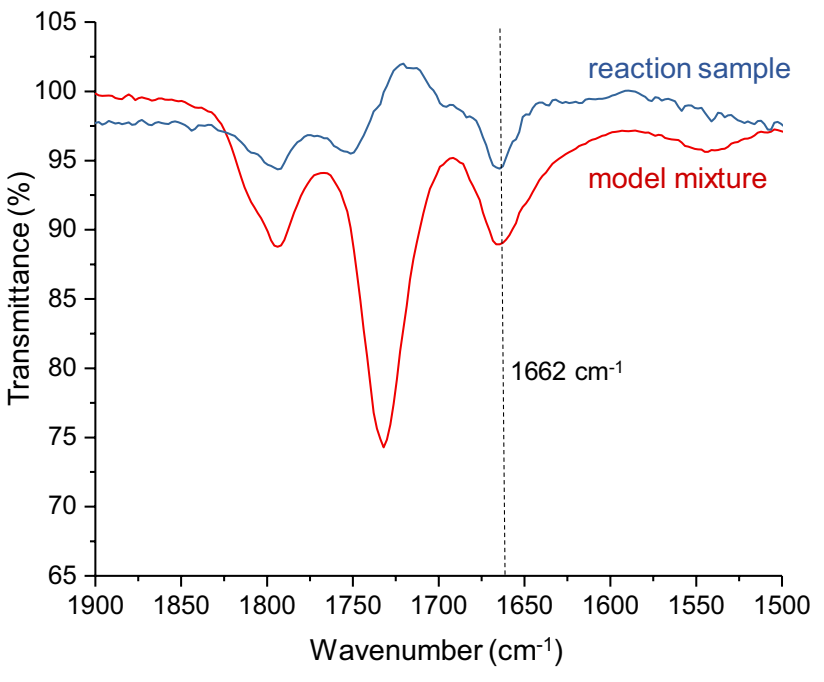

Fig. 6 FTIR spectra of reaction mixtures (liquid samples) obtained from the direct carboxylation of pure glycerol with $\mathrm{CO}_{2}$ in the presence of adiponitrile (raction sample, blue), and the reaction of glycerol carbonate and adiponitrile in present of $\mathrm{CO}_{2}$ (model mixture, red). Reaction conditions: $\mathrm{P}=4.5 \mathrm{MPa}, 6 \mathrm{wt} . \%$ of $\mathrm{La}_{2} \mathrm{O}_{3}, 2.1 \mathrm{~g}$ of glycerol or glycerol carbonate, $45 \mathrm{mmol}$ of adiponitrile. The reaction was carried out at $160{ }^{\circ} \mathrm{C}$ for $18 \mathrm{~h}$. The peak at $1662 \mathrm{~cm}^{-1}$ is indicative of the presence of an amide product

amidic group $(\mathrm{N}-\mathrm{C}=\mathrm{O})$ and hence this suggests a secondary by-product from glycerol carbonate and adiponitrile [19]. In order to test this hypothesis, glycerol carbonate and adiponitrile were reacted directly in both the presence and absence of $\mathrm{CO}_{2}$. FTIR analysis of this reaction mixture (Fig. 6), clearly shows the presence of a peak at $1662 \mathrm{~cm}^{-1}$, thus supporting this assumption. The formation of 4-HMO is a consequence of the reaction of ammonia, resulting from adiponitrile decomposition, and 2,3-dihydroxypropyl hydrogen carbonate. As adiponitrile is used for both crude and pure glycerol reactions it should not be surprising this species is detected in both these mixtures, although in lower amount when pure glycerol is used. The same rationale applies for the interpretation of FT-IR data from reaction mixtures containing methanol where 4-HMO is also detected (Sect. 3.5). This is furthermore supported by GC-MS analysis where two unidentified product peaks were detected.

\subsection{Carboxylation of Model Crude Glycerol}

In order to understand and determine the impact of the impurities present in crude glycerol on the reaction, model crude glycerol feedstocks have been prepared comprising glycerol and the known impurities [2, 9]. In addition, glycerol feedstock standards have been prepared with each impurity present individually, in order to ascertain their effect in the absence of mutual interactions. Additionally, feedstocks with two impurities present simultaneously were also prepared 
to allow an analysis of the interplay between these effects. The impurities added are: methanol, methyl palmitate (as a model FAME), water and sodium methoxide. The quantities of each impurity have been selected in order for their impact to be clearly evident. These individual effects can then be correlated with the differences observed between crude and pure glycerol discussed in Sect. 3.3.

Table 2 shows the impact of each impurity considered individually on catalytic performance. It is possible to observe that impurities of methyl palmitate, water and sodium methoxide, all decrease the selectivity of the reaction towards glycerol carbonate. In contrast the addition of methanol does not have a detrimental effect on either measured selectivity, which increases from 17 to $22 \%$, or on conversion, which increases from 58 to $61 \%$. It is a noteworthy that there is likely to be improved mass transfer in the presence of methanol as a consequence of a higher miscibility of glycerol and $\mathrm{CO}_{2}$. In fact, $\mathrm{CO}_{2}$ is only slightly miscible in glycerol [53], however the equilibrium of $\mathrm{CO}_{2}$, methanol and glycerol is improved in favour of dissolved $\mathrm{CO}_{2}$ upon increasing methanol concentration [54]. Additionally, methanol may also inhibit secondary reactions of glycerol carbonate thereby increasing the reaction selectivity. We anticipate a more detailed study on the effect of methanol in order to determine its precise role. In the present study, further evidence of enhanced selectivity to glycerol carbonate is discussed in Sect. 3.6.

The impact of $1 \mathrm{wt} . \%$ sodium methoxide on the carboxylation reaction is to reduce both conversion (51\%) and selectivity to glycerol carbonate $(11 \%)$ instead. The reduced selectivity to glycerol carbonate is reflected in an eightfold increase in the quantity of 4-HMO. As sodium methoxide acts as a homogeneous catalyst in biodiesel synthesis, the efficacy of this species as a catalyst for the direct conversion of glycerol was tested by repeating the reaction in the absence of $\mathrm{La}_{2} \mathrm{O}_{3}$ (Table 2). A $43 \%$ conversion of glycerol was observed - a decrease of less than $10 \%$ as compared to the reaction using $\mathrm{La}_{2} \mathrm{O}_{3}$, in the absence of sodium methoxide. However, the selectivity to glycerol carbonate was further reduced to $6.8 \%$. Sodium methoxide therefore acts as an active homogeneous catalyst for glycerol conversion, but by altering the selectivity compared with $\mathrm{La}_{2} \mathrm{O}_{3}$ in favour of 4-HMO. This effect may arise through two possible mechanisms: firstly, $\mathrm{NaOCH}_{3}$ can react with glycerol carbonate to induce ring opening reactions, in turn reducing the selectivity towards glycerol carbonate and thus indirectly increasing the selectivity towards 4-HMO. An alternative parallel pathway is an acid-base reaction between 2,3-dihydroxypropyl hydrogen carbonate and the methoxide, with the formation of a carboxylic salt which would not be able to proceed to glycerol carbonate formation. The second possible mechanism to explain the effect of sodium methoxide in the formation of 4-HMO is via a cyclization step $\left(-\mathrm{NH}_{2}\right.$ attack of the carbonyl group) which comprises the formation of a transition state with a large charge separation: $\left[-\mathrm{NH}_{2}(+)-\right.$ $\mathrm{CO}(-)-\mathrm{OH}]^{\ddagger}$. Sodium methoxide could stabilise this transition state, and in turn decrease the activation energy of this step, or directly promote the removal of a $\mathrm{H}^{+}$species from this transition state and in turn promote product formation.

The addition of $10 \mathrm{wt} . \%$ FAME to the glycerol reactant resulted in a strong increase of conversion up to $76 \%$; however, selectivity to glycerol carbonate drops to only $1 \%$. Due to the high conversion and low selectivity to glycerol carbonate, it is proposed that the glycerolysis of fatty acid methyl esters to monoglycerides occurs during the reaction [55, 56]. FTIR analysis (Fig. 7) was conducted in order to investigate the origin of this reduced selectivity to glycerol carbonate. In comparison to the reaction with pure glycerol the peak at $1790 \mathrm{~cm}^{-1}$ (ascribed to $\mathrm{C}=\mathrm{O}$ of glycerol carbonate) is no longer present. This coincides with a reduced intensity of the peak at $1730 \mathrm{~cm}^{-1}(\mathrm{C}=\mathrm{O}$ of 4-HMO $)$ and with the appearance of new peaks at $1715 \mathrm{~cm}^{-1}, 1360 \mathrm{~cm}^{-1}$ and $1220 \mathrm{~cm}^{-1}$. The band at $1715 \mathrm{~cm}^{-1}$ is typical of a carbonyl group of a ketone $\left(\mathrm{R}_{2} \mathrm{C}=\mathrm{O}\right)$ stretch, while the peaks at 1360 and $1220 \mathrm{~cm}^{-1}$ are characteristic of nitro- $\left(\mathrm{RNO}_{2}\right)$ and phenolic species respectively. The absence of a band at $1790 \mathrm{~cm}^{-1}$ is consistent with the low selectivity towards glycerol carbonate and hence the role that FAMEs play in hindering glycerol carbonate formation.

The influence of water on the reaction has also been investigated. The addition of $10 \mathrm{wt} . \%$ of water in the reaction mixture resulted in a significant decrease in glycerol conversion to $19 \%$ and glycerol carbonate selectivity to $2.6 \%$. This

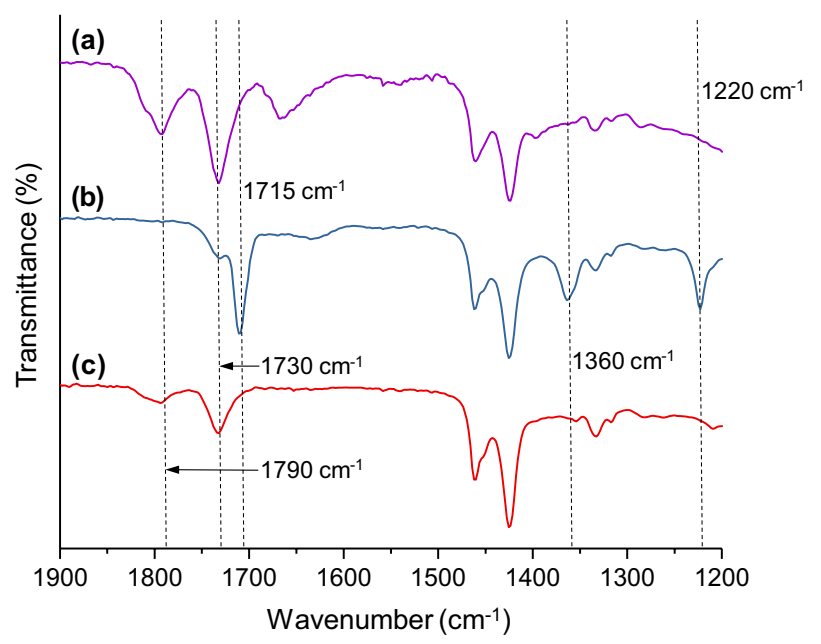

Fig. 7 FTIR spectra of reaction mixtures (liquid samples) from the reaction of glycerol with impurities and $\mathrm{CO}_{2}$ over $\mathrm{La}_{2} \mathrm{O}_{3}$ catalyst. a No impurities present; b with methyl palmitate impurity; $\mathbf{c}$ with methyl palmitate and methanol impurities. The peaks at $1790 \mathrm{~cm}^{-1}$, $1730 \mathrm{~cm}^{-1}, 1715 \mathrm{~cm}^{-1}, 1360 \mathrm{~cm}^{-1}$ and $1220 \mathrm{~cm}^{-1}$ are ascribed to $\mathrm{C}=\mathrm{O}$ of glycerol carbonate, $\mathrm{C}=\mathrm{O}$ of $4-\mathrm{HMO}, \mathrm{R}_{2} \mathrm{C}=\mathrm{O}, \mathrm{RNO}_{2}$, and phenolic species respectively 
is likely attributable to the selective strong adsorption of water molecules on the active sites of $\mathrm{La}_{2} \mathrm{O}_{3}$ [39] leading to catalyst deactivation.

Water and FAMEs have a negative impact on the carboxylation of glycerol and significantly reduced the selectivity to glycerol carbonate from $17 \%$ to $<3 \%$. The presence of sodium methoxide also reduces glycerol carbonate selectivity: to $11 \%$ and $6.8 \%$ in the presence and absence of the $\mathrm{La}_{2} \mathrm{O}_{3}$ respectively. This decrease is correlated with an increase in the formation of 4-HMO and other by-products. In contrast, the addition of methanol to the reaction mixture has no such detrimental effect and results in glycerol conversion and glycerol carbonate selectivity of $61 \%$ and $22 \%$ respectively.

As the impurities in crude glycerol are likely to interact with one another, and with any subsequent products produced from the impurities, the behaviour of model feedstocks containing two or more impurities has also been investigated. In this case, the presence of methanol is kept constant across all model systems with glycerol and methanol in an 80:20 molar ratio.

Using these conditions, the addition of 1 wt.\% sodium methoxide does not have the same stark reduction in glycerol carbonate selectivity as it does in the absence of methanol. Indeed, this system has the highest selectivity of any system investigated in this work (25\%), although this occurs at a cost of a reduced conversion of $46 \%$ as compared to $58 \%$ for pure glycerol, and $61 \%$ for the glycerol/methanol mixture. In contrast, the addition of FAME results in a significantly reduced selectivity alongside high conversion, as it was observed in the absence of methanol. This trend is also observed if methanol, sodium methoxide and FAME are all present; suggesting that the effect of FAME is to reduce glycerol carbonate selectivity.

In contrast to a reaction mixture containing methyl palmitate as a single impurity, the FTIR spectrum for the sample containing methanol and the FAME (Fig. 7) does not show significant intensity at $1715 \mathrm{~cm}^{-1}$. This suggests that the previously observed ketone functionality is not formed in the presence of methanol, or that it is rapidly consumed. When the reaction mixture comprises glycerol, methanol, FAME and $\mathrm{CO}_{2}$, the phenolic $\left(1360 \mathrm{~cm}^{-1}\right)$ and nitro- $\left(1220 \mathrm{~cm}^{-1}\right)$ moieties are not observed by FTIR again confirming the impact of these impurities on the reaction.

The addition of sodium methoxide to glycerol/methanol mixture increases the selectivity to glycerol carbonate, from 22 to $25 \%$; while the addition of FAME results in a decrease in the selectivity to glycerol carbonate to $3.4 \%$ (Table 3 ). The most complex model feedstock; comprising of glycerol, methanol, sodium methoxide and FAME yields only $4 \%$ selectivity to glycerol carbonate, again confirming that the presence of FAME reduces glycerol carbonate selectivity. Complete separation of FAME, i.e. biodiesel is therefore both commercially advantageous to increase biodiesel yield and to facilitate conversion of the glycerol by-product.

\subsection{Influence of Additives on the Conversion of Crude Glycerol}

Given the observation that methanol does not diminish, and may slightly increase, the efficiency of the carboxylation reaction with respect to glycerol carbonate production when compared with the use of pure glycerol, the influence of the addition of methanol to crude glycerol was also investigated (Fig. 8). The addition of $5 \mathrm{wt} . \%$ methanol to crude glycerol resulted in a decrease in glycerol conversion to $38 \%$; this is coupled with an increase in selectivity to glycerol carbonate to $10 \%$. In this study the reaction time is kept constant at $18 \mathrm{~h}$. It is therefore necessary to be cautious when comparing selectivities among different reactions as the overall conversions achieved differ significantly. The increase in selectivity is however in agreement with studies utilising model feedstocks, where feeds containing a binary mixture of impurities including methanol achieved higher selectivities than those containing only sodium methoxide of FAMEs as the impurity (Tables 2 and 3).

The comparison of FTIR spectra for the reaction mixtures post-reaction liquid samples (Fig. 9) from the reactions involving: (a) crude glycerol mixed with methanol and (b) pure glycerol mixed with methanol, shows that the peak at $1790 \mathrm{~cm}^{-1}$ (glycerol carbonate) is not observed in the sample arising from crude glycerol. However, bands with strong intensities are observed for the peaks at $1730 \mathrm{~cm}^{-1}$ (4-HMO) and $1662 \mathrm{~cm}^{-1}$ (the peak at $1662 \mathrm{~cm}^{-1}$ has previously been

Table 3 The impact of multiple impurities on carboxylation of glycerol over $\mathrm{La}_{2} \mathrm{O}_{3}$. Reaction conditions: $\mathrm{P}=4.5 \mathrm{MPa}, 6$ wt.\% of $\mathrm{La}_{2} \mathrm{O}_{3}-\mathrm{C}$, glycerol:methanol (22.5 mmol in total) and $45 \mathrm{mmol}$ of adiponitrile and $18 \mathrm{~h}$

\begin{tabular}{llll}
\hline Feedstock composition & $\begin{array}{l}\text { Conversion of glycerol } \\
(\%)\end{array}$ & $\begin{array}{l}\text { Selectivity to glycerol } \\
\text { carbonate (\%) }\end{array}$ & $\begin{array}{l}\text { Yield of glyc- } \\
\text { erol carbonate } \\
(\%)\end{array}$ \\
\hline Glycerol + methanol (80:20 ratio) + 1 wt.\% sodium methoxide & 46 & 25 & 12 \\
Glycerol + methanol (80:20 ratio) + 10 wt.\% FAME & 85 & 3.4 & 2.9 \\
Glycerol + methanol (80:20 ratio) + 10 wt.\% FAME +1 wt.\% sodium & 73 & 4.0 & 2.9 \\
methoxide & & \\
\hline
\end{tabular}



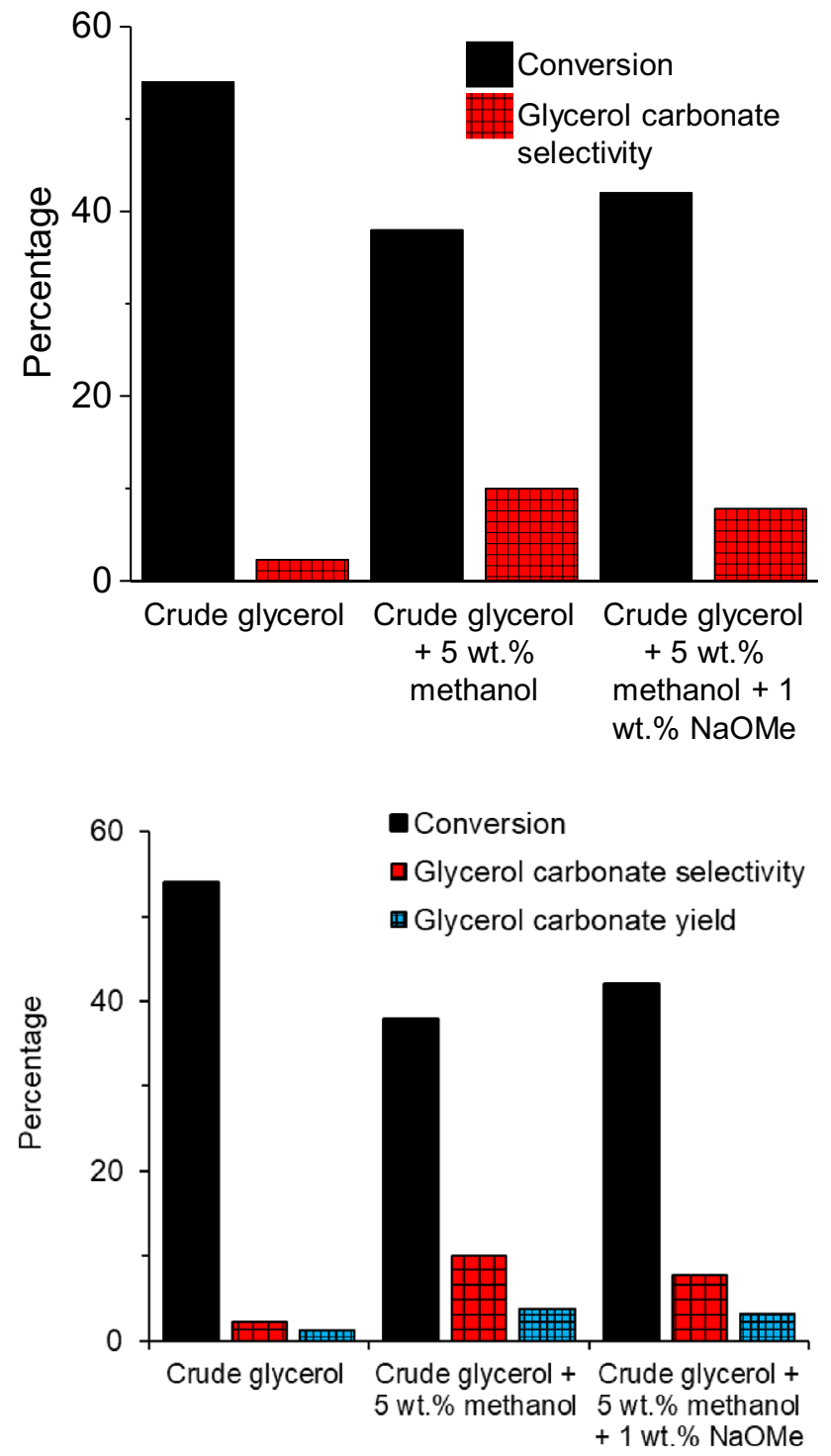

Fig. 8 Conversion of glycerol, selectivity and yield to glycerol carbonate for crude glycerol and crude glycerol plus methanol and sodium methoxide. Reaction conditions: $\mathrm{P}=4.5 \mathrm{MPa}, 6$ wt. $\% \mathrm{La}_{2} \mathrm{O}_{3}$, $2.1 \mathrm{~g}$ glycerol, $5 \mathrm{wt} \%$ methanol, $1 \mathrm{wt} . \%$ of sodium methoxide, $5 \mathrm{ml}$ adiponitrile; reaction $\mathrm{T}=160^{\circ} \mathrm{C}$, reaction time $=18 \mathrm{~h}$

assigned to an amide product formed from glycerol carbonate) [19]. This may therefore support the suggestion that the lower selectivity observed is indicative of the secondary conversion of synthesised glycerol carbonate to such products rather than an absence of formation of this product.

The addition of both $1 \mathrm{wt}$.\% sodium methoxide and methanol to the crude glycerol has the effect of increasing conversion relative to the sample with only methanol added from 38 to $43 \%$, while decreasing selectivity to glycerol carbonate from 10 to $7.8 \%$. Note that for all reactions employing crude glycerol, conversion and selectivity follow an inverse correlation with selectivity decreasing with increased conversion.

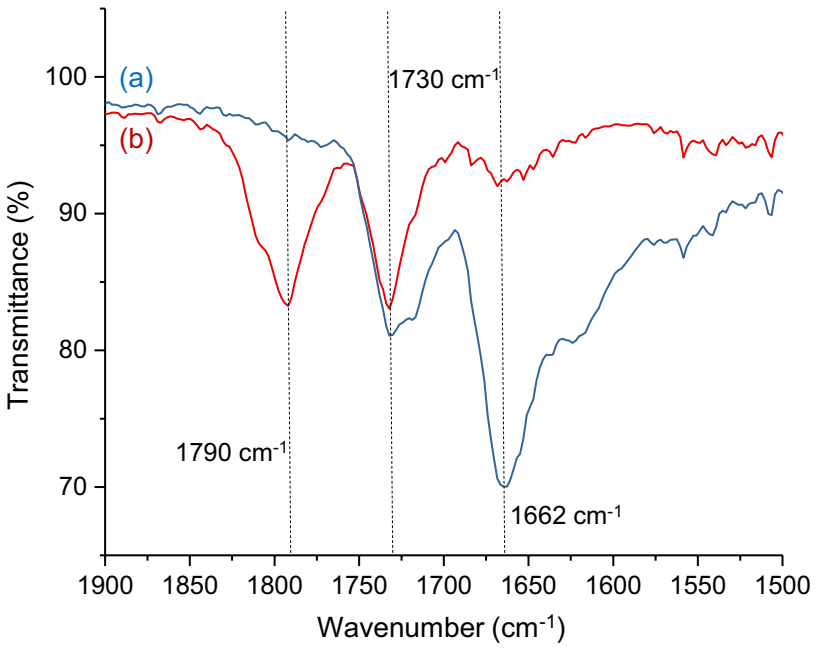

Fig. 9 FTIR spectra of a the reaction of crude glycerol and 5 wt.\% of methanol and $\mathrm{CO}_{2}$ and $\mathbf{b}$ the direct carboxylation of pure glycerol: methanol to the molar ratio of 80:20. Reaction conditions: $\mathrm{P}=4.5 \mathrm{MPa}, 6$ wt. $\% \mathrm{La}_{2} \mathrm{O}_{3}, 80: 20$ glycerol:methanol or $2.1 \mathrm{~g}$ of crude glycerol and 5 wt. $\%$ of methanol, $5 \mathrm{ml}$ adiponitrile; reaction $\mathrm{T}=160{ }^{\circ} \mathrm{C}$, reaction time $=18 \mathrm{~h}$

This trend may indicate that the main influence of the additives is alter the overall rate of reactions(s) rather than alter the reaction pathways [9]. A detailed investigation of different times-on-stream, which is outwith the scope of this work, would provide insights into this. The overall impact of sodium methoxide is less pronounced than in the model feedstock systems. Overall, additives may act to increase the selectivity of the reaction but further investigation is required to confirm this effect and determine its origin.

\section{Conclusions}

In this work, the efficacy of $\mathrm{La}_{2} \mathrm{O}_{3}$ as a catalyst for the synthesis of glycerol carbonate via the carboxylation of crude glycerol was demonstrated for the first time. The carboxylation of crude glycerol shows a significantly lower selectivity to glycerol carbonate (2.3\%) as compared to using pure glycerol where a selectivity of $17 \%$ was obtained. In order to understand the impact of impurities on glycerol conversion and product selectivity, several model crude glycerol feedstocks containing one or more impurities (water, methanol, sodium methoxide and FAME) were prepared. The addition of methanol slightly increased the measured selectivity from 17 to $22 \%$. Water, sodium methoxide and FAME lowered the glycerol carbonate selectivity to $<10 \%$. Glycerol conversion increased upon the addition of FAME to $76 \%$, but only $1 \%$ selectivity to glycerol carbonate was observed. FTIR analysis confirmed the presence of additional by-products. Interestingly, sodium methoxide was able to synthesise glycerol carbonate even in the absence of 
$\mathrm{La}_{2} \mathrm{O}_{3}$; therefore sodium methoxide can act as a homogeneous catalyst in this process. The selectivity to glycerol carbonate in this case is however greatly reduced, with sodium methoxide instead favouring the formation of 4-HMO.

As the impurities in crude glycerol are also likely to interact with one another, model feedstocks comprising of sodium methoxide and/or FAME were also investigated. In this work the presence of methanol was kept constant across all model systems with glycerol and methanol in an 80:20 molar ratio. A similar trend is observed from the reaction of glycerol, methanol and FAME in comparison with the reaction of glycerol and FAME. This suggests that the presence of FAME lowers the selectivity to glycerol carbonate. The introduction of $5 \mathrm{wt} . \%$ methanol to the crude glycerol improved the selectivity to glycerol carbonate from 2.3 to $10 \%$. Overall, FAME and sodium methoxide have a detrimental effect on the carboxylation of crude glycerol; but methanol has no such negative impact. Further investigation is required to confirm the impact of these impurities and understand the mechanistic origin of these observations.

Acknowledgements The SEM data presented were acquired with the support of the Engineering and Physical Sciences Research Council (EPSRC) "4CU" programme grant, aimed at sustainable conversion of carbon dioxide into fuels, led by The University of Sheffield and carried out in collaboration with University College London, the University of Manchester, and Queen's University Belfast. The authors acknowledge the EPSRC for supporting this work financially (Grant No. EP/ K001329/1). NR gratefully acknowledges the Ministry of Education, Malaysia for the award of a PhD scholarship.

Open Access This article is distributed under the terms of the Creative Commons Attribution 4.0 International License (http://creativeco mmons.org/licenses/by/4.0/), which permits unrestricted use, distribution, and reproduction in any medium, provided you give appropriate credit to the original author(s) and the source, provide a link to the Creative Commons license, and indicate if changes were made.

\section{References}

1. Sankaranarayanan S, Srinivasan K (2012) Carbon dioxide-a potential raw material for the production of fuel, fuel additives and bio-derived chemicals. Indian J Chem 51 A:1252-1262

2. Luo X, Ge X, Cui S, Li Y (2016) Value-added processing of crude glycerol into chemicals and polymers. Bioresour Technol 215:144-154

3. He Q, McNutt J, Yang J (2017) Utilization of the residual glycerol from biodiesel production for renewable energy generation. Renew Sustain Energy Rev 71:63-76

4. Quispe CAG, Coronado CJR, Carvalho JA (2013) Glycerol: production, consumption, prices, characterization and new trends in combustion. Renew Sustain Energy Rev 27:475-493

5. Ciriminna R, Della Pina C, Rossi M, Pagliaro M (2014) Understanding the glycerol market. Eur J Lipid Sci Technol 116:1432-1439

6. Tan HW, Abdul Aziz AR, Aroua MK (2013) Glycerol production and its applications as a raw material: a review. Renew Sustain Energy Rev 27:118-127
7. Krämer K, Marquardt W (2008) Syntheserahmenwerk zum Entwurf von destillativen Trennprozessen für azeotrope Vielstoffgemische (Kennziffer 2728)

8. Indran VP, Saud ASH, Maniam GP, Taufiq-Yap YH, Rahim MHA (2016) Viable glycerol carbonate synthesis through direct crude glycerol utilization from biodiesel industry. Waste Biomass Valor $8: 1-11$,

9. Teng WK, Ngoh GC, Yusoff R, Aroua MK (2016) Microwaveassisted transesterification of industrial grade crude glycerol for the production of glycerol carbonate. Chem Eng J 284:469-477

10. Valerio O, Horvath T, Pond C, Misra M, Mohanty A (2015) Improved utilization of crude glycerol from biodiesel industries: synthesis and characterization of sustainable biobased polyesters. Ind Crops Prod 78:141-147

11. Szymanowska-Powałowska D (2014) 1,3-Propanediol production from crude glycerol by Clostridium butyricum DSP1 in repeated batch. Electron J Biotechnol 17:322-328

12. Khanna S, Goyal A, Moholkar VS (2013) Production of $n$-butanol from biodiesel derived crude glycerol using Clostridium pasteurianum immobilized on Amberlite. Fuel 112:557-561

13. Sonnati MO, Amigoni S, Taffin de Givenchy EP, Darmanin T, Choulet O, Guittard F (2013) Glycerol carbonate as a versatile building block for tomorrow: synthesis, reactivity, properties and applications. Green Chem 15:283-306

14. Ochoa-Gómez JR et al (2009) Synthesis of glycerol carbonate from glycerol and dimethyl carbonate by transesterification: catalyst screening and reaction optimization. Appl Catal A Gen 366:315-324

15. Zhang Z, Rackemann DW, Doherty WOS, O'Hara IM (2013) Glycerol carbonate as green solvent for pretreatment of sugarcane bagasse. Biotechnol Biofuels 6:153

16. Yadav GD, Chandan PA (2014) A green process for glycerol valorization to glycerol carbonate over heterogeneous hydrotalcite catalyst. Catal Today 237:47-53

17. Malyaadri M, Jagadeeswaraiah K, Sai Prasad PS, Lingaiah N (2011) Synthesis of glycerol carbonate by transesterification of glycerol with dimethyl carbonate over $\mathrm{Mg} / \mathrm{Al} / \mathrm{Zr}$ catalysts. Appl Catal A Gen 401:153-157

18. Narkhede N, Patel A (2015) Facile synthesis of glycerol carbonate via glycerolysis of urea catalysed by silicotungstates impregnated into MCM-41. RSC Adv 5:52801-52808

19. Indran VP et al (2014) An accelerated route of glycerol carbonate formation from glycerol using waste boiler ash as catalyst. RSC Adv 4:25257-25267

20. Hammond C et al (2011) Synthesis of glycerol carbonate from glycerol and urea with gold-based catalysts. Dalt Trans 40:3927-3937

21. Climent MJ et al (2010) Chemicals from biomass: Synthesis of glycerol carbonate by transesterification and carbonylation with urea with hydrotalcite catalysts. The role of acid-base pairs. J Catal 269:140-149

22. Simanjuntak FSH, Widyaya VT, Kim CS, Ahn BS, Kim YJ, Lee $\mathrm{H}$ (2013) Synthesis of glycerol carbonate from glycerol and dimethyl carbonate using magnesium-lanthanum mixed oxide catalyst. Chem Eng Sci 94:265-270

23. Hasbi Ab Rahim MH et al (2012) Gold, palladium and goldpalladium supported nanoparticles for the synthesis of glycerol carbonate from glycerol and urea. Catal Sci Technol 2:1914-1924

24. Saiyong P, Liping Z, Renfeng N, Shuixin X, Ping C, Zhaoyin $H$ (2012) Transesterification of glycerol with dimethyl carbonate to glycerol carbonate over $\mathrm{Na}$-based zeolites. Chinese $\mathrm{J}$ Catal 33:1772-1777

25. Liu J, Li Y, Zhang J, He D (2016) Glycerol carbonylation with $\mathrm{CO}_{2}$ to glycerol carbonate over $\mathrm{CeO}_{2}$ catalyst and the influence of $\mathrm{CeO}_{2}$ preparation methods and reaction parameters. Appl Catal A Gen 513:9-18 
26. Earth's $\mathrm{CO}_{2}$ Home Page. [Online]. https://www.co2.earth/. Accessed 27 Jun 2018

27. Li J, Wang T (2010) Coupling reaction and azeotropic distillation for the synthesis of glycerol carbonate from glycerol and dimethyl carbonate. Chem Eng Process Process Intensif 49:530-535

28. Li J, Wang T (2011) Chemical equilibrium of glycerol carbonate synthesis from glycerol. J Chem Thermodyn 43:731-736

29. $\mathrm{Li} \mathrm{H}$ et al (2013) The synthesis of glycerol carbonate from glycerol and $\mathrm{CO}_{2}$ over $\mathrm{La}_{2} \mathrm{O}_{2} \mathrm{CO}_{3}-\mathrm{ZnO}$ catalysts. Catal Sci Technol 3:2801-2809

30. Da Silva E, Dayoub W, Mignani G, Raoul Y, Lemaire M (2012) Propylene carbonate synthesis from propylene glycol, carbon dioxide and benzonitrile by alkali carbonate catalysts. Catal Commun 29:58-62

31. Su X et al (2017) Metal-free catalytic conversion of $\mathrm{CO}_{2}$ and glycerol to glycerol carbonate. Green Chem 19:1775-1781

32. Vieville C, Yoo JW, Pelet S, Mouloungui Z (1998) Synthesis of glycerol carbonate by direct carbonatation of glycerol in supercritical $\mathrm{CO}_{2}$ in the presence of zeolites and ion exchange resins. Catal Lett 60:245-247

33. Dibenedetto A, Angelini A, Aresta M, Ethiraj J, Fragale C, Nocito F (2011) Converting wastes into added value products: from glycerol to glycerol carbonate, glycidol and epichlorohydrin using environmentally friendly synthetic routes. Tetrahedron 67:1308-1313

34. Aresta M, Dibenedetto A, Nocito F, Pastore C (2006) A study on the carboxylation of glycerol to glycerol carbonate with carbon dioxide: the role of the catalyst, solvent and reaction conditions. J Mol Catal A Chem 257:149-153

35. Zhang J, He D (2014) Surface properties of $\mathrm{Cu} / \mathrm{La}_{2} \mathrm{O}_{3}$ and its catalytic performance in the synthesis of glycerol carbonate and monoacetin from glycerol and carbon dioxide. J Colloid Interface Sci 419:31-38

36. Zhang J, He D (2014) Synthesis of glycerol carbonate and monoacetin from glycerol and carbon dioxide over $\mathrm{Cu}$ catalysts: the role of supports. J Chem Technol Biotechnol 90:1077-1085

37. $\mathrm{Li} \mathrm{H}$ et al (2015) Direct carbonylation of glycerol with $\mathrm{CO}_{2}$ to glycerol carbonate over $\mathrm{Zn} / \mathrm{Al} / \mathrm{La} / \mathrm{X}(\mathrm{X}=\mathrm{F}, \mathrm{Cl}, \mathrm{Br})$ catalysts: the influence of the interlayer anion. J Mol Catal A Chem 402:71-78

38. Li H et al (2014) Synthesis of glycerol carbonate by direct carbonylation of glycerol with $\mathrm{CO}_{2}$ over solid catalysts derived from $\mathrm{Zn} / \mathrm{Al}(\mathrm{M}=\mathrm{Li}, \mathrm{Mg}$ and $\mathrm{Zr}$ ) hydrotalcites. Catal Sci Technol 5:989-1005

39. Okoye PU, Abdullah AZ, Hameed BH (2017) Stabilised ladle furnace steel slag for glycerol carbonate synthesis via glycerol transesterification reaction with dimethyl carbonate. Energy Convers Manag 133:477-485

40. Li Q, Zhang W, Zhao N, Wei W, Sun Y (2006) Synthesis of cyclic carbonates from urea and diols over metal oxides. Catal Today 115:111-116

41. Wang L, Ma Y, Wang Y, Liu S, Deng Y (2011) Efficient synthesis of glycerol carbonate from glycerol and urea with lanthanum oxide as a solid base catalyst. Catal Commun 12:1458-1462

\section{Affiliations}

\section{N. A. Razali ${ }^{1} \cdot$ M. Conte ${ }^{2} \cdot$ J. McGregor ${ }^{1}$}

\author{
J. McGregor \\ james.mcgregor@sheffield.ac.uk
}

1 Department of Chemical and Biological Engineering, University of Sheffield, Mappin Street, Sheffield S1 3JD, UK
42. Singh D, Reddy B, Ganesh A, Mahajani S (2014) Zinc/lanthanum mixed-oxide catalyst for the synthesis of glycerol carbonate by transesterification of glycerol. Ind Eng Chem Res 53:18786-18795

43. Zhang J, He D (2015) Synthesis of glycerol carbonate and monoacetin from glycerol and carbon dioxide over $\mathrm{Cu}$ catalysts: the role of supports. J Chem Technol Biotechnol 90:1077-1085

44. Chaudhary D, Adhikari B (2010) Effect of temperature and plasticizer molecular size on moisture diffusion of plasticized-starch biopolymer. Starch Stärke 62:364-372

45. Mu Q, Wang Y (2011) Synthesis, characterization, shapepreserved transformation, and optical properties of $\mathrm{La}(\mathrm{OH})_{3}$, $\mathrm{La}_{2} \mathrm{O}_{2} \mathrm{CO}_{3}$, and $\mathrm{La}_{2} \mathrm{O}_{3}$ nanorods. J Alloys Compd 509:396-401

46. Gangwar BP, Palakollu V, Singh A, Kanvah S, Sharma S (2014) Combustion synthesized $\mathrm{La}_{2} \mathrm{O}_{3}$ and $\mathrm{La}(\mathrm{OH})_{3}$ : recyclable catalytic activity towards Knoevenagel and Hantzsch reactions. RSC Adv 4:55407-55416

47. Manoilova OV et al (2004) Surface acidity and basicity of $\mathrm{La}_{2} \mathrm{O}_{3}$, $\mathrm{LaOCl}$, and $\mathrm{LaCl}_{3}$ characterized by IR spectroscopy, TPD, and DFT calculations. J Phys Chem B 108:15770-15781

48. Gotti A, Prins R (1998) Basic metal oxides as co-catalysts in the conversion of synthesis gas to methanol on supported palladium catalysts. J Catal 175:302-311

49. Mekhemer GAH (2002) Surface structure and acid-base properties of lanthanum oxide dispersed on silica and alumina catalysts. Phys Chem Chem Phys 4:5400-5405

50. Joshi H, Moser BR, Toler J, Walker T (2010) Preparation and fuel properties of mixtures of soybean oil methyl and ethyl esters. Biomass Bioenerg 34:14-20

51. Knothe G (2008) 'Designer' biodiesel: optimizing fatty ester composition to improve fuel properties. Energy Fuels 22:1358-1364

52. Nguyen-Phu H, Park C, Eun WS (2016) Activated red mud-supported $\mathrm{Zn} / \mathrm{Al}$ oxide catalysts for catalytic conversion of glycerol to glycerol carbonate: FTIR analysis. Catal Commun 85:52-56

53. Nunes AVM, Carrera GVSM, Najdanovic-Visak V, Ponte M, Nunes D (2013) Solubility of $\mathrm{CO}_{2}$ in glycerol at high pressures. Fluid Phase Equilib 358:105-107

54. Pinto LF, Ndiaye PM, Ramos LP, Corazza ML (2011) Phase equilibrium data of the system $\mathrm{CO}_{2}+$ glycerol + methanol at high pressures," J Supercrit Fluids 59:1-7

55. Ferretti CA, Apesteguía CR, Di Cosimo JI (2011) MgO-based catalysts for monoglyceride synthesis from methyl oleate and glycerol: effect of Li promotion. Appl Catal A Gen 399:146-153

56. Bancquart S, Vanhove C, Pouilloux Y, Barrault J (2001) Glycerol transesterification with methyl stearate over solid basic catalysts I. Relationship between activity and basicity. Appl Catal A Gen 218:1-11

Publisher's Note Springer Nature remains neutral with regard to jurisdictional claims in published maps and institutional affiliations.

2 Department of Chemistry, University of Sheffield, Brook Hill, Sheffield S3 7HF, UK 